\title{
Experimental check of possibility of research of repeated inclusion of the open gas generator in the water environment
}

\author{
Sergey Goldaev ${ }^{1}$, Vitaly Barsukov ${ }^{2}$, Sergey Basalaev ${ }^{2 *}$, Natalya Minkova $^{2}$ \\ ${ }^{1}$ National Research Tomsk Polytechnic University, 634050 Tomsk, Russia \\ ${ }^{2}$ National Research Tomsk State University, 634050 Tomsk, Russia
}

\begin{abstract}
Experimental study of repeated burning interruption with the subsequent ignition in the water environment for bibasic firm fuel as a part of a model open solid propellant gas generator is presented. Video filming of burning zone mobile localizer providing process of repeated inclusion of a gas generator are given. Some parameters of the processes proceeding in these conditions are defined
\end{abstract}

\section{Introduction}

One of ways of giving of lifting force to the sunk or emergency objects, as we know, is use of the different tanks filled by compressed air. Attempts to use for this purpose more effective gas-generating systems on solid fuel have the essential shortcoming connected with difficulty to carry out the dosed pressurization in any portions of products of burning [1-4]. So, in one of the last large inventions in this area it is offered to use set from six separate gas generators allowing to carry out pressurization respectively in six receptions [5].

Solution of the problem of pressurization of tanks of buoyancy is represented more preferable if to use source of working body with possibility of repeated inclusion. Such sources were developed generally in relation to missile systems [6-9].

Analysis of scientific and technical literature shows that the majority of currently known solid sources of gases such as rocket motors or to multiple use inclusion of gas generators has common disadvantages, namely the complexity of the design and the limited number of inclusions. In one cases the number of starts unambiguously is defined by quantity of heatinsulated sections of fuel, in others, at implementation of extinguishing of charge, - amount of igniters. Besides, all known solid-fuel sources of gases, especially and with repeated inclusion, in case of their use in underwater conditions, have restrictions on the working depth of immersion about $5 \ldots 6 \mathrm{~km}$.

It is possible to get rid of these shortcomings at the expense of enough simple technical means in specific conditions of burning of unitary solid fuel directly in the water environment. So, in work [8] the way repeated interruption of burning and repeated ignition of sample of solid fuel in the water environment and for its implementation is offered the

* Corresponding author: tarm@niipmm.tsu.ru 
key diagram of open solid-fuel gas generator with the mobile localizer of zone of gasification (MLZG) is provided. On the basis of this method in [8] implemented parametric analysis of controlled lifting the wreck deep pontoon, blown by means of the gas generator with multiple inclusion. At the same time, the offered way of underwater burning of unitary solid fuel demands further improvement.

The purpose of this work is experimental study of the processes involved in the ignition and the interruption of the combustion and the subsequent ignition in the water environment checkers dibasic solid fuel being a part of model open solid propellant gas generator multiple inclusion.

\section{Device description}

As the object of the study was used a model version of the open solid fuel gas generator incorporating multiple, depicted in Fig. 1 in the operating position, at the start of the next ignition fuel checkers. Gas generator consists of a shaped support 1 with a mounted thereon a cylindrical checker dibasic solid fuel 2, thereon which is set up warming movable localizer of zone of gasification. MLZG contains a container 3 with an internal electric heater, made in the form of ceramic rod 4. On the ceramic rod is wound a spiral filament 5 with lead wires 6 . Electric heater at the side surface and the upper end is insulated asbestos 7. Rest of the space of the container 3 are filled with epoxy resin 8 . At the bottom of the container 3 to weight located wire winding 9 and the external asbestos insulation 10. To the bottom of the container 3 is attached cylinder 11, which has a side windows 13 . Lower part of the cylinder 11 are formed as guide 14 .

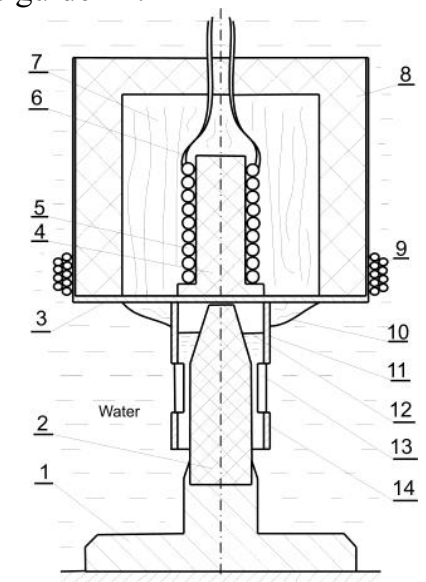

Fig. 1. Scheme model of an open solid-fuel gas generator in the beginning of the second ignition fuel checkers placed in the water environment.

\section{Testing of the model device}

When tested in a model gas generator was placed in a water-filled container with transparent walls. At placement of installation under water special attention to that the beaker 11 has been completely filled with water, including the working volume of beaker (height of working part of beaker made $17.6 \mathrm{~mm}$ ). This ensured the condition of the first ignition of fuel does directly in the water environment.

The samples used in the experiment was a cylindrical grain of dibasic solid fuel with a diameter of $20 \mathrm{~mm}$ and height $60 \mathrm{~mm}$. Electric power delivered to the filament 5 was 350 W. 
Process was recorded on video digital camera "NIKON" with a frequency of 60 frames per second. The separate video footage illustrating provisions MLZG in the course of functioning of model solid-fuel gas generator is given in fig. 2. Under the video frames, given an appropriate time for the various stages of operation: the ignition mode, the combustion mode, the withdrawal mode MLZG.

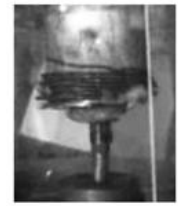

Ignition

$0.1 \mathrm{~s}$

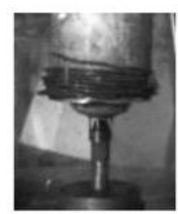

Withdrawal 24.5...29,3 s

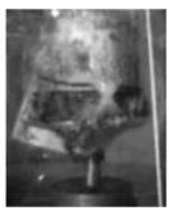

Combustion $56.7 \ldots 61.0 \mathrm{~s}$

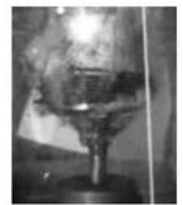

Combustion $0.1 \ldots 5.8 \mathrm{~s}$

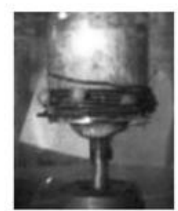

Ignition $29.3 \ldots 37.1 \mathrm{~s}$

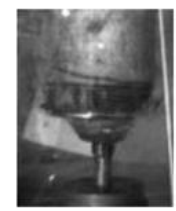

Withdrawal $61.0 \ldots 66.6 \mathrm{~s}$

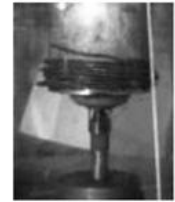

Withdrawal $5.8 \ldots 11.1 \mathrm{~s}$

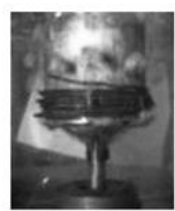

Combustion $37.1 \ldots 41.0 \mathrm{~s}$

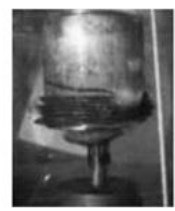

Ignition $66.6 \ldots 83.7 \mathrm{~s}$

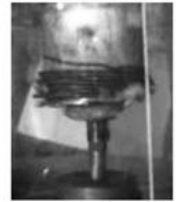

Ignition $11.1 \ldots 19.6 \mathrm{~s}$

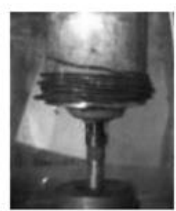

Withdrawal $41.0 \ldots 46.7 \mathrm{~s}$

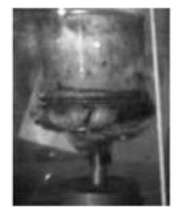

Combustion $83.7 \ldots 89.5 \mathrm{~s}$

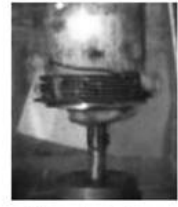

Combustion $19.6 \ldots 24.5 \mathrm{~s}$

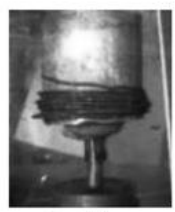

Ignition $46.7 \ldots .56 .7 \mathrm{~s}$

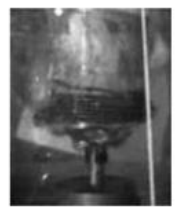

Withdrawal $89.5 \ldots 93.3 \mathrm{~s}$

Fig. 2. Characteristic video frames illustrating the position MLSG in the process of functioning of model solid propellant gas generator with the ignition, combustion and extinction of fuel.

According to the video with an absolute error no more than $0.5 \mathrm{~mm}$ was determined according to time of the provisions MLSG in the process of multiple interrupts combustion and subsequent ignition of the fuel. Immediate results shown in Fig. 3 (experimental values indicated by dots), which some times lack of movement MLSG more ignition timing. This was due to a mechanical braking MLSG. Therefore, the ignition timing were corrected based on video frames, retaining the appearance of gas bubbles. The revised data is shown in Fig. 4. While in both figures the Y-axis was postponed distance from the upper plane of the base of the shaped support 1 to the lower edge of the guide 14 . 


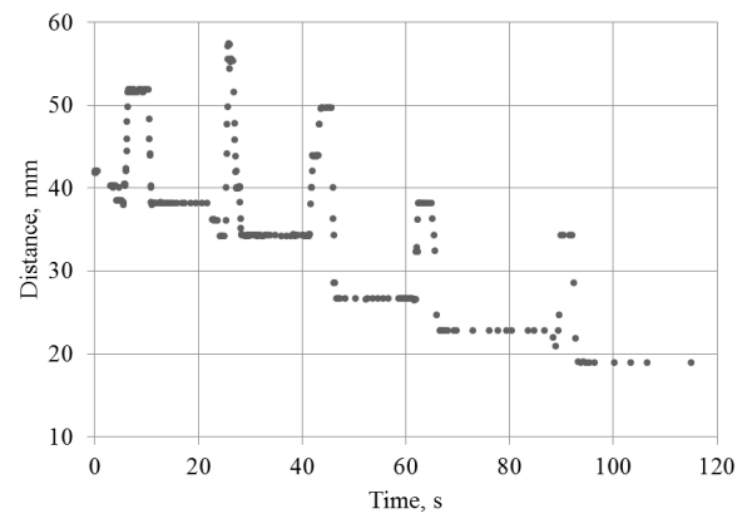

Fig. 3. Experimental points the position MLSG at different points in time in underwater ignition, combustion and extinction of fuel.

For illustration of idea of process it is more convenient to use the specified schedule in fig. 4. Inclusion of video camera has been made for saving of time of shooting at the moment when there were first bubbles of products of burning (point A in fig. 4). Then, in connection with the beginning of combustion, MLZG under the influence of curb weight moves with fuel combustion speed down. Further, (point B) MLZG withdrawal up, some time is maintained at any distance, and then again falls by fuel sample (point C). During warming up there is secondary ignition of fuel (point D) and therefore MLZG starts over again to move down (point E). Another lowering MLSG on the fuel checker in F point for the subsequent ignition. In the future, there is an alternation the ignition mode, the combustion mode, the withdrawal mode MLZG.

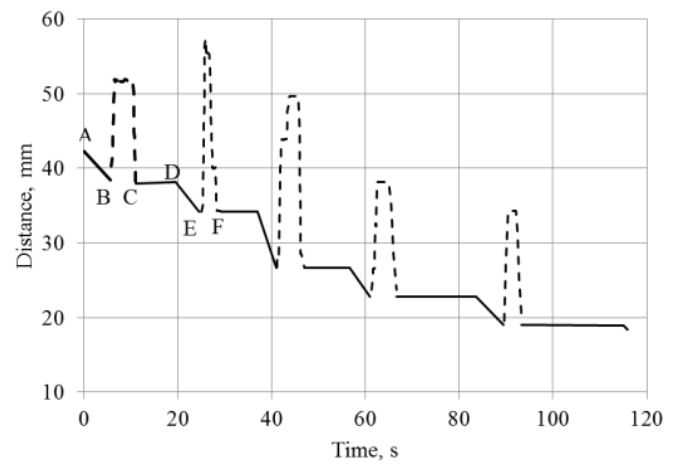

Fig. 4. Schedule of time dependence of situation MLSG at underwater ignition, combustion and extinction of fuel.

By results of video filming some parameters of functioning of gas generator which are provided in the enclosed table have been calculated.

Tests of gas generator on the different modes has shown rather wide spacing in time of the first ignition of fuel checker $(\approx 10 \ldots 20 \mathrm{~s})$. Comparison of information received from fig. 2 and 3 allows to define ignition time at different stages of inclusion of gas generator. Time re-ignition determined with a relative error less than $3 \%$, were of the same order with the time of first ignition.

The first ignition is carried out at full filling of working volume of beaker with water. Therefore the part of heat energy is spent for its evaporation, at least, in the layers adjacent to MLZG bottom. Remains liquid is then forced out generated by combustion products. 
Follows from the made experiments that repeated ignition is carried out ranging from 8.5 to $22.9 \mathrm{~s}$.

Table 1. Some operation parameters of the model solid propellant gas generator in underwater ignition, combustion and extinction of fuel.

\begin{tabular}{|c|c|c|c|c|}
\hline No. & $\begin{array}{c}\text { Ignition time } \\
t_{3}, \mathrm{~s}\end{array}$ & $\begin{array}{c}\text { Combustion time } \\
t, \mathrm{~s}\end{array}$ & $\begin{array}{c}\text { MLZG } \\
\text { motion } \\
\text { speed } \\
U, \mathrm{~mm} / \mathrm{s}\end{array}$ & $\begin{array}{c}\text { MLZG } \\
\text { withdrawal } \\
\text { speed, } \\
U_{0}, \mathrm{~mm} / \mathrm{s}\end{array}$ \\
\hline 1 & $10 \ldots 20$ & 5.7 & 0.68 & 8.2 \\
\hline 2 & 8.5 & 5.0 & 0.79 & 14.3 \\
\hline 3 & 7.8 & 3.9 & 1.91 & 6.6 \\
\hline 4 & 10.0 & 4.3 & 0.90 & 14.6 \\
\hline 5 & 17.1 & 5.9 & 0.64 & 13.4 \\
\hline 6 & 22.9 & - & - & - \\
\hline
\end{tabular}

The high speed of the movement MLZG at the third stage of combustion attracts attention. We may assume that this rate corresponds to the cone combustion mode.

MLZG withdrawal speed in averaged $11.4 \mathrm{~mm} / \mathrm{c}$, so the extinction time is in the range of $2.7 \mathrm{~s}$. There is question of the motion speed of the front of extinction. Obviously, when driving MLSG up front fading fuel is moved at a speed close to the speed of rise of the water level adjacent to the sample. Some lag is in limits of time of change of personnel making less than $0.07 \mathrm{~s}$.

\section{Conclusion}

Thus, studies conducted have revealed the peculiarities of the open model of the gas generator based on dibasic solid fuel in water with repeated starting and stopping. Shows an approximate estimate of the rate of motion MLZG change during the transition from the end surface gasification, the fuel combustion rate equal to the cone-shaped, depending on the conditions of the first stage of combustion. It is shown that the retraction of the movable localizer area gassing up at a speed of from 6.6 to $14.6 \mathrm{~mm} / \mathrm{s}$ the extinction of the fuel is carried out for a time from 2.7 to $1.2 \mathrm{~s}$, while the retard of extinction relative movement MLSG does not exceed $0.07 \mathrm{~s}$ [10]. Time and again the following ignitions is from 8.5 to $22.9 \mathrm{~s}$.

The reported study was funded by RFBR according to the research project No. 16-03-00630a.

\section{References}

1. V. M. Bukalov, A.A. Narusbayev, Design of nuclear submarines (Shipbuilding, Leningrad, 1968)

2. I. Delgrende, Bull. A. Ssol Techn. mer etacronaut. 72, 369 (1972)

3. A.S. 664873 USSR, MKI2 V63S 07/08. Rigid pontoon for rise sunk objects / E. Bril, V. N. Govorushkin, O. I. Kalinin, etc. Zayav. 05.01.78; Opubl. 30.05.79. Bulletin No. 20. 2 p.

4. E.V. Dobrozrakova, A.N. Zharinov, V. M. Kulyukin, Questions of defense equipment. It is gray 1, 50 (1992)

5. The patent No. 2134212 Russian Federation System of emergency emersion of Malachite-1 submersibles, the device for blowing off of tanks of the main ballast at emergency emersion and way of emergency emersion/VA. Sirotkin, A.A. Tyurikov, N. I. Homenko, Yu.A. Zakharov. Zayavl. 25.08.98. Opubl. 10.08.99. 
6. A.A. Shishkov, Gas generators of missile systems (Mechanical engineering, Moscow, 1981)

7. V.D. Barsukov, S.V. Goldaev, Scuba unitary ignition and combustion of solid fuels. Theory, experiment, technical proposals (Publishing house of Tomsk, Tomsk, 2003)

8. V.D. Barsukov, S.V. Goldaev, N.P. Min'kova, S.A. Basalaev, Underwater burning solid fuels dibasic (Publishing house of Tomsk, Tomsk, 2016)

9. V.D. Barsukov, S.V. Goldaev, N.P. Min'kova, S.A. Basalaev, Chem. phys. mesoscopy 14, 327 (2012)

10. V.D. Barsukov, S.V. Goldaev, N.P. Min'kova, S.A. Basalaev, Chem. phys. mesoscopy 17, $166(2015)$ 